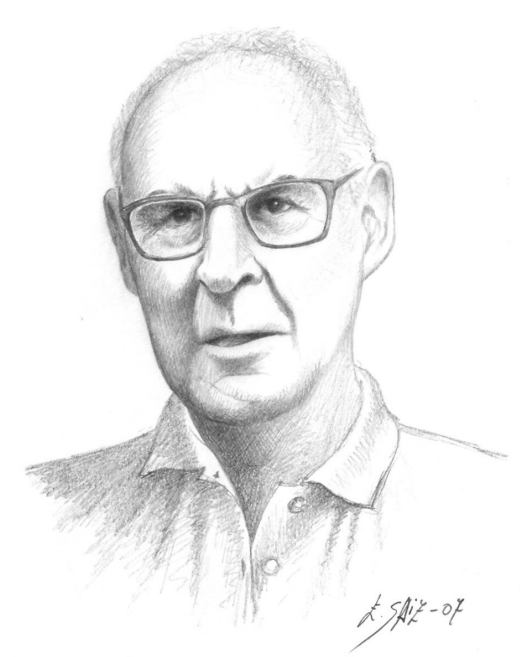

\title{
Emiliano Aguirre Enríquez. In memoriam
}

El pasado 11 de octubre nos dejaba a los 96 años Emiliano Aguirre Enríquez, una persona imprescindible para poder entender el gran salto científico que se produce en España en la segunda mitad del siglo XX. Con su muerte desaparece un intelectual y un amigo, un investigador que ha trabajado mucho y bien para conocer el pasado de los seres humanos y, al mismo tiempo, un maestro de las actuales personas que nos dedicamos a la Prehistoria.

Vamos a dar sólo unos breves apuntes biográficos, ya que con ocasión de su muerte se han publicado numerosos obituarios que tratan en extenso su vida y sus aportaciones. Además, en el homenaje a Emiliano Aguirre (Zona Arqueológica 4, de 2005) varios artículos glosaron su inmensa figura, que puede ser complementada por un artículo de acceso libre en arqueoweb (Villaescusa, 2011) y una estupenda entrevista en el Museo Arqueológico Regional de Madrid (Baquedano-MAR, 2012). Una aproximación a sus ideas sobre la evolución humana, escritas en su juventud se publicaron en la BAC (Crusafont et al., 1966). Su obra principal de la edad madura, puede encontrarse en un manual universitario en Espasa (Aguirre, 2008). Aquí queremos compartir lo que hemos vivido con él y lo que hemos conocido de él a través de él mismo o de otros sabios.

Emiliano (como dice Baquedano, a todos nos sobraban los apellidos para referirnos a él) nace en Ferrol, el año en el que, como a él le gustaba decir, ve la luz Australopithecus africanus. Raymond Dart publica en 1925 el fósil de un niño recuperado en la cantera de Taung, en Sudáfrica. Desde ese momento, África gana protagonismo sobre Asia en la búsqueda de las raíces de la humanidad. África siempre estuvo en el imaginario de Emiliano ("África es un imán intenso"): primero quiso ir allí de Misionero, después participó en proyectos a inicios de los 60, con ocasión de la construcción de la presa de Asuán, que supusieron su aprendizaje en la arqueología; por último, pudo viajar y estudiar de primera mano los yacimientos y los fósiles de homínidos de la mano del mencionado Dart o de la familia Leakey que le apreciaron siempre con especial respeto y cariño como colega y amigo. Se dice que Louis y Mary Leakey se relajaron cuando Emiliano aceptó acompañar a su hijo Richard a Turkana donde pronto encontraron nuevos yacimientos.

Aguirre entra muy joven en los jesuitas y cursa las carreras de Ciencias Naturales y de Filosofía. Siempre habló con pasión de sus dos maestros, Bermudo Meléndez y su director de tesis, Miquel Crusafont. Esta tesis, presentada en la Complutense de Madrid, en 1966, versaba sobre elefantes fósiles, fue sintetizada en la revista Science y le permitió viajar por numerosos países y ver no sólo fósiles y sitios, también a los grandes científicos internacionales y observar los métodos para formar equipos y diseñar proyectos. Aquéllos que más le agradaron, eran los que mezclaban disciplinas, en lo que se denominaba perspectiva interdisciplinar, aunados sobre un mismo marco ecológico y con un objetivo en común. Emiliano hizo su tesis sobre los elefantes, pero podría haberla realizado sobre múltiples temas y áreas de conocimiento. Él mismo comentaba que había barajado diversas posibilidades de tesis y que se decantó por aquella que en ese momento le ofrecieron y era posible.

En los años 60 Emiliano hace mucha geología en Granada y Zaragoza, Arqueología en Nubia, Porriño y en Torralba, Paleontología en París, Nairobi, Moscú o Budapest, Antropología en Perú y por todas partes ciencia y filosofía. Además y por si fuera poco, se empeñaba en educación y en divulgación. Es decir, la formación y el aprendizaje operativo que tenía, le hubiera permitido acometer muchas tesis doctorales. Cuando uno revisa las tesis que dirigió (más completo el listado contenido en Zona Arqueológica 2 que el de Dialnet), es posible apreciar que geología, paleontología y arqueología, de diferentes momentos temporales, caminaban por su cerebro con total comodidad. Su gran memoria, su capacidad de interrelacionar conocimientos y hallazgos, incluso los más recónditos, nunca nos dejaron de asombrar.

Abandona los jesuitas en 1974, pero no la fe en Dios. Siempre nos comentó que para él (como para otros darwinistas como Francisco Ayala) nunca supuso un problema combinar su firme y erudito conocimiento de la evolución, que defendió con pasión, con la creencia de que existía un plan del creador, a la manera en que lo formulaba el teólogo francés Teilhard de Chardín, a quien consideraba su referente Revista Atlántica-Mediterránea de Prehistoria y Arqueología Social 23, pp. 7-11 Universidad de Cádiz 


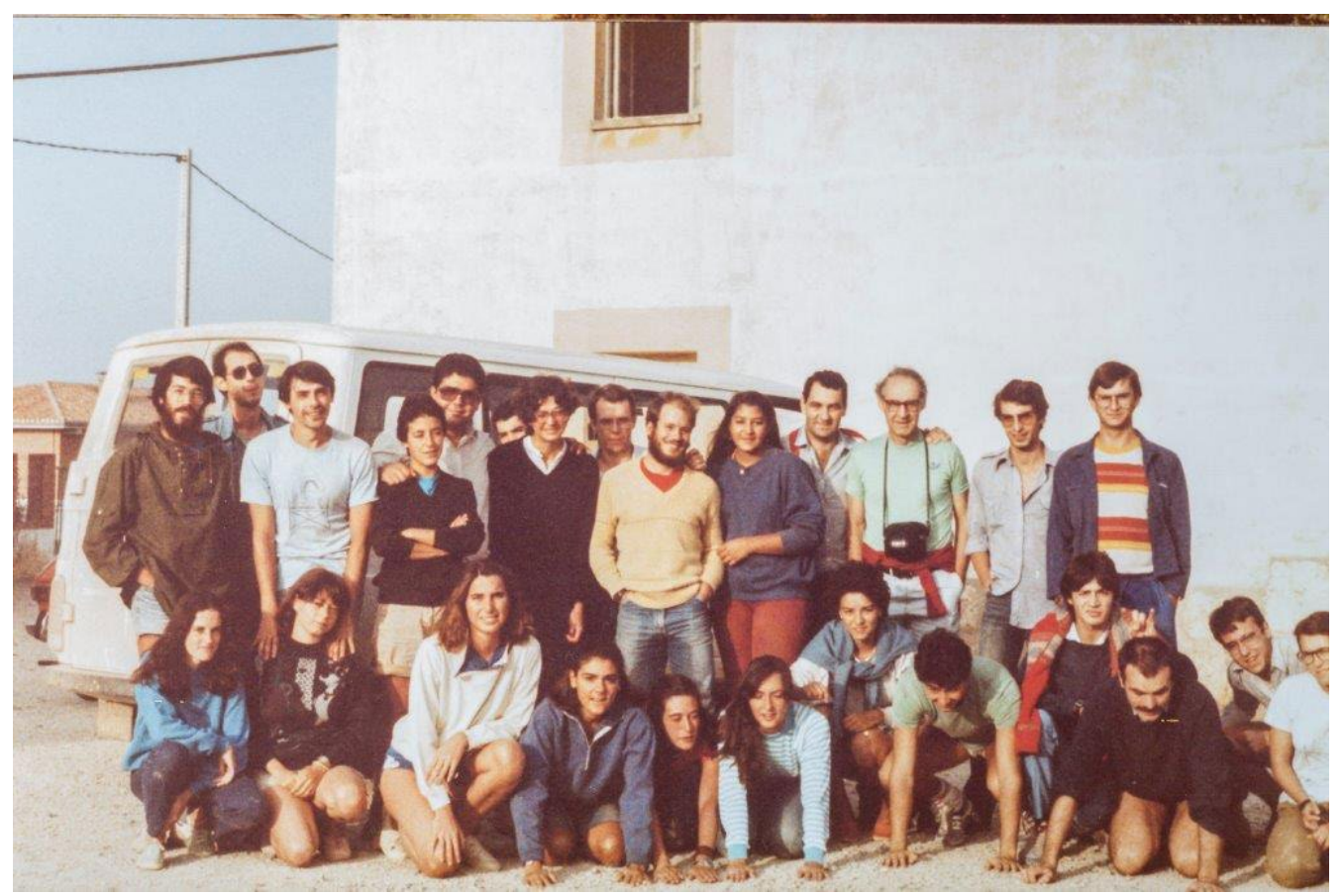

Excavadores en Ibeas de Juarros. Campaña de 1984. Aguirre está en la fila superior, tercero por la derecha.

para aunar ciencia y teología. Tampoco tuvo especiales discusiones sobre ese tema con la orden. Él nos decía que, al contrario que en otros colectivos religiosos, siempre se sintió animado y cómodo con sus superiores en lo tocante al estudio y a sus intereses científicos. Siempre declaró que se decantó por las Ciencias Naturales por iniciativa de la orden y que para él era un orgullo haber sido jesuita, por la enorme labor social que habían desarrollado en el continente americano desde los tiempos de José de Acosta, S.J. Peor llevaba su espíritu acatar mandatos en los que él no se sentía a gusto y tuvo frecuentes intercambios de ideas con desavenencias cuando le ordenaban que hiciera lo que no deseaba.

El amor por Carmen Bule seguro que influyó en su decisión de dejar los jesuitas, en menor medida consagrarse a la ciencia y a su estudio. Muy poco debió intervenir en su decisión ese choque de un carácter fuerte como el suyo frente a la autoridad de los superiores. En nada intervino su probada creencia en un ser superior. Saberes y fe siempre le acompañaron (Aguirre, 2011).

Esta década del 70 le permite a Emiliano plasmar buena parte de lo aprendido en sus viajes por todo el mundo y también lo que había desarrollado junto a su amigo Clark Howell en Torralba y Ambrona. Tras su paso por varias facultades y ciudades, con encargos de curso, entra en el Instituto Lucas Mallada del CSIC en Madrid en 1974, ganando la Cátedra de Paleontología de Zaragoza en 1978. Sólo estuvo un año en Zaragoza, pero de allí procederán buena parte de los estudiantes que van a acompañarle los primeros años de las excavaciones de Atapuerca.

Ha sido múltiples veces relatado cómo Trinidad Torres, ingeniero de minas, es conducido por el Grupo Espeleológico Edelweiss a la Sima de los Huesos, en la Sierra de Atapuerca. Con Carlos Puch encuentran allí varios fósiles humanos asociados a un oso típico del Pleistoceno medio. Se los enseñan a Aguirre, quien con rapidez confirma la humanidad y antigüedad de los fósiles, comenzando un proyecto de investigación en 1978 que se consolida a partir de 1980. El núcleo duro está conformado por Eudald Carbonell, arqueólogo de Gerona, a quien ha conocido en el congreso de Morella, y un grupo de Paleontólogos y geólogos del Instituto Lucas Mallada, como Enrique Soto, Dolores Soria, Carmen Sesé, Jorge Morales, Caridad Zazo o Manolo Hoyos. Los pocos estudiantes venimos de Burgos (Aurora Martín y Carlos Díez), Cataluña (Julià Maroto, Robert Sala) y Zaragoza (Enrique Gil), entre otros. Al ganar la cátedra de Paleontología en la complutense de Madrid (1982), se incorporarán con posterioridad Arsuaga y Bermúdez de Castro y estudiantes como Antonio Rosas, Yolanda Fernández e Ignacio Martínez.

Emiliano va a centrarse en estos años en la reforma del Museo Nacional de Ciencias Naturales, como director interino (1985-86), la presidencia de la comisión del INQUA, para definir el límite del Plio-Pleistoceno (aprobado en la sesión de 1985 con una fecha de 1,8 M.a.), la dirección de tesis desde su plaza 
de Profesor de Investigación del CSIC (1984-1990) y la dirección del Proyecto Atapuerca hasta 1991. Muchos frentes que le permitieron desarrollar con plenitud todas las facetas que han hecho de él un referente para las generaciones siguientes.

El Museo catalogó muchísimos de los restos que tenía desde principios de siglo, en particular los de la Comisión de Prehistoria. Persiguió la dejadez, ejemplificada en los robos que se descubrieron de sus láminas y manuscritos. La abrió a la sociedad, remodelando, desde una perspectiva expositiva, las diferentes salas temáticas y recuperando la magnificencia de sus colecciones con una importancia histórica y científica sin igual, hasta entonces almacenadas bajo capas de polvo y apiladas sin orden ni cuidado.

El consenso obtenido con el límite Plio-Pleistoceno le catapultó, aún más a nivel internacional. Como toda fecha, es muy discutible, pero hizo gala de enormes dosis de trabajo y de mano izquierda, hablándoles en su idioma (inglés, francés, italiano, ruso e incluso alemán), cediendo donde era pertinente, para lograr un veredicto que pudiera satisfacer a la inmensa mayoría de los geólogos. Fueron muchas las reuniones que tuvo que realizar y sólo el voto de un español (i) impidió la aprobación sin votos en contra.

El trabajo realizado en Atapuerca era también muy duro. Con poco apoyo de instituciones, pero también con muchas zancadillas de colegas (el listado no es aquí pertinente). Con muy poco dinero, pero sin desfallecer, Emiliano sabía que Atapuerca prometía y se vió obligado a hacer de maestro de una cuadrilla de jóvenes a los que inculcó el amor al trabajo interdisciplinar, la paciencia y la humildad para reconocer que sabíamos poco y que había que seguir investigando y que no éramos mejores que nadie, por lo que debíamos tratar a todo el mundo con respeto. La confianza y orgullo en los estudiantes, a quienes nos presentaba como grandes eruditos, con elevadas palabras que, aunque supiéramos que exageraba, no hacían más que incrementar la admiración que ya teníamos por Emiliano y nuestra obligación con él por ser los mejores. Unió como nadie la Paleontología y la Arqueología, disciplina esta última a la que consideraba, por método, muy cerca de las denominadas ciencias, ya que usa lo experimental.

Los grandes hallazgos llegaron después de su jubilación, pero una docena de tesis doctorales sobre Atapuerca estaban muy avanzadas o leídas. Los estratos estériles y las zonas revueltas se habían retirado. Las opiniones de los colegas se estaban matizando, los pueblos aledaños veían con orgullo que la sierra despuntaba en publicaciones y los periodistas y vecinos se acercaban a los días de puertas abiertas y a las ruedas de prensa de fin de campaña.

Para Emiliano la jubilación consistía en seguir trabajando pero cobrando menos y tenía claro que no iba a hacer de "reina madre" en el proyecto Atapuerca. Preparó con mimo el traspaso de poderes, involucrando a Arsuaga, Bermúdez de Castro y Carbonell en el último trienio del proyecto. Como él decía, eran los más preparados y los únicos que disponían de una nómina mensual dentro del núcleo científico del Proyecto.

Llegó en 1997 el Premio Príncipe de Asturias de Investigación Científica y Técnica, en principio destinado al "Equipo de Atapuerca liderado por el Prof. Emiliano Aguirre", y que quedó finalmente "al Equipo de Atapuerca", para Emiliano constituido por casi un centenar de miembros que de una u otra manera habían colaborado en el yacimiento, a los que uno a uno escribió haciéndoles partícipes del premio. En 1999 recibe la Medalla de Oro al Mérito en el Trabajo de la mano del entonces ministro Manuel Pimentel, ferviente admirador de lo que representaba Emiliano.

Después vino su nombramiento como Académico de la Real Academia de Ciencias Exactas, Físicas y Naturales de Madrid, como antes lo fue su director, Don Bermudo Meléndez; los doctorados Honoris causa por las universidades de A Coruña y Burgos; los homenajes de sus discípulos en Dinópolis (Teruel, 2009), en el Museo Nacional de Ciencias Naturales y el CSIC (Madrid, 2015); los volúmenes de homenaje del Museo Arqueológico Regional de Madrid; o actos de reconocimiento como hijo predilecto del Ferrol y Burgos. Una calle pegada al Museo de la Evolución Humana lleva su nombre en Burgos, lo mismo que otra en Ibeas de Juarros que conduce a los yacimientos.

El legado científico de Emiliano es enorme, pero hay un par de aspectos que queremos resaltar. No creía en la parcelación del saber más allá del marco operativo, es decir, hay que especializarse para dominar al máximo una faceta, pero nunca olvidarse que conocer al ser humano es una labor cooperativa, multidisciplinar, en la que muchas personas deben colaborar juntas, huyendo de explicaciones basadas en un solo campo del conocimiento. En segundo lugar, es necesario aproximarse a la gente y mostrar nuestro trabajo a los demás, comunicar lo que se va sabiendo. El conocimiento se expande. Es una batalla en la que no podemos desfallecer ni dejarnos atrapar por la pereza o el ego. Hay que mover voluntaRevista Atlántica-Mediterránea de Prehistoria y Arqueología Social 23, pp. 7-11 Universidad de Cádiz 


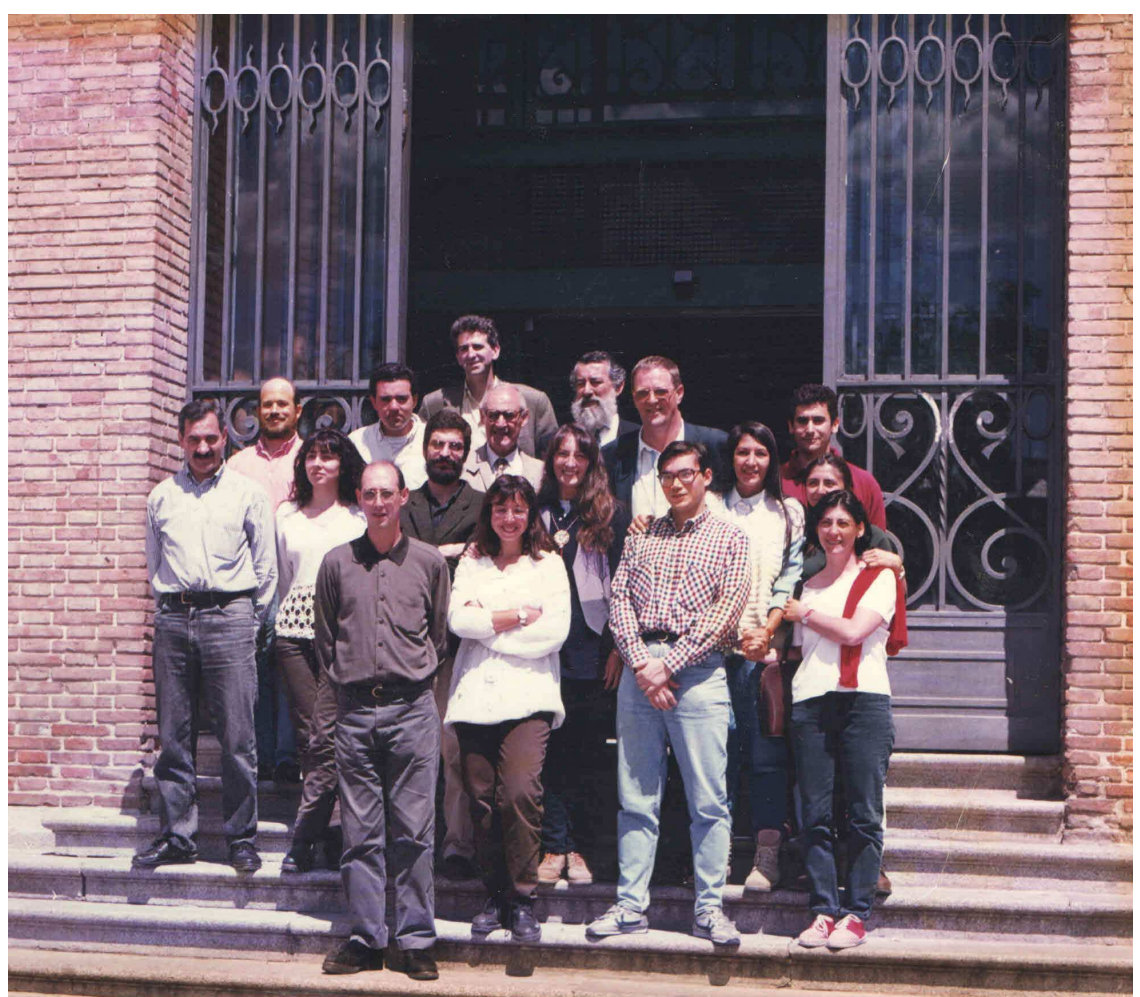

Equipo Investigador de Atapuerca en Madrid en octubre de 1997. Nos juntamos en las escaleras del Museo Nacional de Ciencias Naturales junto al entonces director del Museo, Rodríguez de Calella. Aguirre está en el centro de la imagen, en el cuarto peldaño.

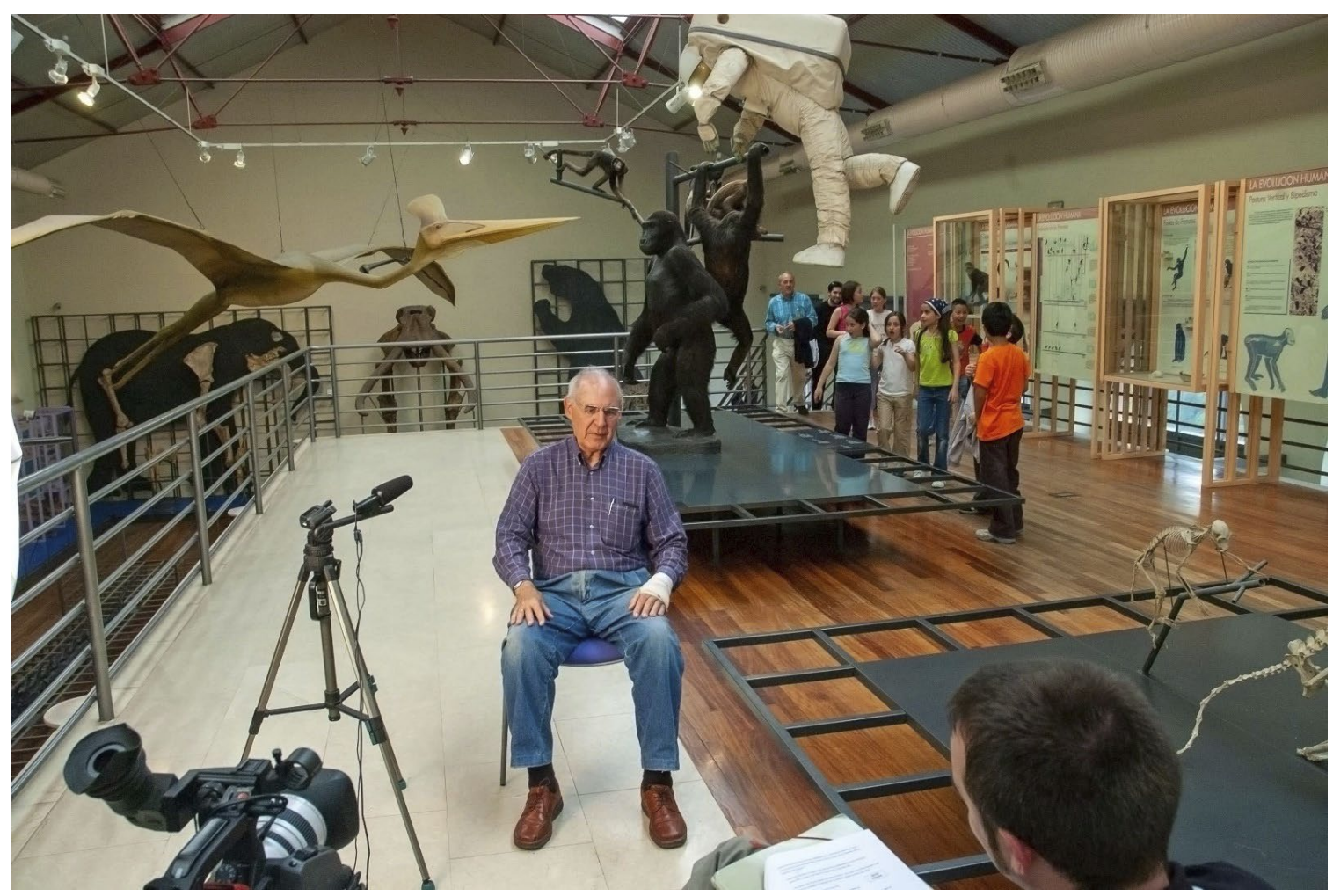

Entrevista a Emiliano Aguirre el año 2006 en uno de los ámbitos de su preferencia: en la sala de la Evolución, junto a los escolares, del Museo Nacional de Ciencias Naturales. Foto: Luís Mena/DYSA. 
des con la cercanía a los alcaldes, a los periodistas, a la sociedad en general. Sólo si la sociedad está de nuestra parte podremos presionar a instancias superiores para dignificar la educación y la ciencia.

\section{Bibliografía}

AGUIRRE, Emiliano. 2008: Homo hispánicus. Espasa Calpe S.A. Madrid.

AGUIRRE, Emiliano. 2011: Cooperación entre diversos: regla de la evolución cósmica. Discurso de inicio de curso 2010-2011 en la Real Academia de Ciencias Exactas, Físicas y Naturales. Madrid.

BAQUEDANO, Enrique. 2012: Entrevista a Emiliano Aguirre. https://www.youtube.com/watch?v=gKz9ho-jmCs. Consultado el 14 de octubre de 2021.

BAQUEDANO, Enrique; RUBIO, Susana (eds.). 2002: Emiliano Aguirre. Obra Selecta (1957-2003). Zona Arqueológica 2. Madrid.

CRUSAFONT, Miguel; MELÉNDEZ, Bermudo; AGUIRRE, Emiliano (eds.). 1966: La Evolución. Biblioteca de Autores Cristianos (BAC). Madrid.

MORALES, Jorge; SORIA, Dolores. 2002: “Emiliano Aguirre Enríquez: notas biográficas”. En E. BAQUEDANO y S. RUBIO (eds.): Emiliano Aguirre: obra selecta (1957-2003), pp.12-45. Madrid.

VILLAESCUSA, Lucía. 2011: "Emiliano Aguirre Enríquez. Un paso adelante en la paleoantropología española”. Arqueoweb: Revista sobre Arqueología en Internet, 13(1), p. 108-134. https://dialnet.unirioja. es/servlet/articulo?codigo=3866977\&orden=336168\&info=link. Consultado el 15 de octubre de 2021.

* La ilustración de primera página es un retrato de Eduardo Sáiz realizado en 2007, con base en varias fotografías de los años noventa.

J. CARLOS DÍEZ FERNÁNDEZ-LOMANA Prehistoria. Universidad de Burgos.

YOLANDA FERNÁNDEZ-JALVO

Paleobiología. Museo Nacional de Ciencias Naturales. CSIC. 